\title{
Changes in blood biochemical markers before, during, and after a 2-day ultramarathon
}

This article was published in the following Dove Press journal:

Open Access Journal of Sports Medicine

21 April 2016

Number of times this article has been viewed

\section{Kazuyuki Arakawa ${ }^{1,2}$ \\ Akihiro Hosono ${ }^{2}$ \\ Kiyoshi Shibata ${ }^{3}$ \\ Reza Ghadimi ${ }^{4}$ \\ Mizuho Fuku ${ }^{5}$ \\ Chiho Goto ${ }^{6}$ \\ Nahomi Imaeda ${ }^{7}$ \\ Yuko Tokudome ${ }^{8}$ \\ Hideki Hoshino 9 \\ Mitsuhiro Marumoto ${ }^{1,2}$ \\ Masaaki Kobayashi ${ }^{10}$ \\ Sadao Suzuki \\ Shinkan Tokudome $e^{1,2,11}$}

'Department of Health and Nutrition Policy, ${ }^{2}$ Department of Public Health, Nagoya City

University Graduate School of Medical

Sciences, Nagoya, Japan; ${ }^{3}$ Department

of Public Health and Nutrition, Aichi

Gakusen University, Okazaki, Japan; ${ }^{4}$ Social

Determinants of Health Research Center,

Health Research Institute, Babol University of

Medical Sciences, Babol, Iran; ${ }^{5}$ Department of

Rehabilitation Medicine, Yokohama Stroke and

Brain Center, Yokohama, Japan; ${ }^{6}$ Department

of Health and Nutrition, Nagoya Bunri

University, Inazawa, Japan; ${ }^{7}$ Department of

Food Science and Nutrition, Nagoya Women's University, Nagoya, Japan; ${ }^{8}$ Department of

Nutritional Sciences, Nagoya University

of Arts and Sciences, Nisshin, Japan;

'Department of Early Childhood Studies,

Aichi Bunkyo Women's College, Inazawa,

Japan; ${ }^{10}$ Department of Orthopaedic Surgery,

Nagoya City University Graduate School of

Medical Sciences, Nagoya, Japan; "National

Institute of Health and Nutrition, Tokyo, Japan

Correspondence: Shinkan Tokudome

National Institute of Health and Nutrition,

I-23-I,Toyama, Shinjuku-ku, Tokyo I62-8636,

Japan

Tel $+8|33203572|$

Fax +8 I 332023278

Email tokudome2013@gmail.com
Abstract: We studied changes in blood markers of 18 nonprofessional, middle-aged runners of a 2-day, $130 \mathrm{~km}$ ultramarathon. Blood was sampled at baseline, after the goals on the first and second day, and at three time points (1,3, and 5/6 days) after the race. Blood indices showed three patterns. First pattern indices showed essentially no changes after the two goals and after the race, including red blood cell indices, gamma-glutamyl transferase, and tumor necrosis factor- $\alpha$. Second pattern markers, including the majority of indices, were elevated during the race (and also after the race for some parameters) and then returned to baseline afterward, including hemolysis/red blood cell destruction markers (indirect bilirubin) and an iron reservoir index (ferritin), muscle damage parameters (uric acid, creatine kinase, lactate dehydrogenase, and aspartate aminotransferase), renal function markers (creatinine and blood urea nitrogen), liver injury index (alanine aminotransferase), lipid metabolism indices (free fatty acid), reactive oxygen species and inflammation parameters (white blood cells, interleukin-6, and C-reactive protein), and energy production and catecholamines (adrenaline, noradrenaline, and dopamine). Third pattern index of a lipid metabolism marker triglyceride - decreased during the race periods and started returning to baseline from then onward. Some hormonal markers such as insulin, leptin, and adiponectin showed unique patterns. These findings appeared informative for nonprofessional athletes to know about an optimal physical activity level, duration, and total exercise for elevating physical performance and monitoring physical/ mental conditioning as well as for prevention of overtraining and physical injuries.

Keywords: long-distance running, blood biochemical markers, anemia, muscle damage, lipid metabolism, inflammation

\section{Introduction}

Physical exercise and sports are widely acknowledged to affect not only mental health but also physical condition, including the hematopoietic system, bone, muscle, and various internal organs as well as immune system. ${ }^{1}$ Moderate/optimal physical exercise appears to be beneficial to health, particularly by reducing the risk of developing a number of diseases and syndromes, such as heart disease, obesity, diabetes mellitus, metabolic syndrome, and cancer, ${ }^{2-4}$ whereas excessive physical exercise is unhealthy because it results in physical damage, ${ }^{1}$ mental stress, ${ }^{5,6}$ and oxidative stress or reactive oxygen species (ROS) production. ${ }^{7-11}$

Nonetheless, since athletes suffer from physical damage and mental distress, it seems important for them to explore optimal intensity, duration, and total exercise/ energy expenditure not only for preventing overtraining but also for monitoring fitness and enhancing sports performance. There are studies on the physical and mental effects of endurance exercise, including distance running and triathlon, ${ }^{12-33}$ but here

submit your manuscript | www.dovepress.com 
we investigated changes from baseline and temporal patterns of 36 less-expensive, routinely available blood biochemical markers of nonprofessional, middle-aged, Japanese runners before, during, and 3 weekdays after a consecutive 2-day ultramarathon race with one night of sleep. ${ }^{34}$

\section{Material and methods Participants}

We invited nonprofessional, male Japanese runners participating in the Yashagaike-Densetsu ultramarathon race held in 2004 residing in three Prefectures (Aichi, Gifu, and Mie). Their proximity to our institute made it possible for athletes to be available for an early morning fasting blood sampling on 3 weekdays after the race. Of 41 male athletes recruited, 25 runners agreed to take part in our study. They habitually trained about $240 \mathrm{~km}$ a month on average. We received written informed consent from all subjects. The protocol was approved by the Institutional Review Board of the Nagoya City University Graduate School of Medical Sciences and by the chairman and organizing committee of the race.

\section{Procedures}

Anthropometric measurements (body height and weight) were made before the race. Sampling of venous blood using a vacuum tube with serum-separating medium and with EDTA-2Na was performed at six time points: before the race (baseline), immediately after the goals on the first day (Day 1), on the second day (Day 2), the morning after the race (Day 3 ), the morning 3 days after the race (Day 5), and the morning 5/6 days after the race (Day 7 ).

At baseline and during the race, the subjects were free to consume food and beverages, but after the race, they were asked to fast overnight after 9 pm on the day before blood sampling. Sampled blood was stored frozen at $-80^{\circ} \mathrm{C}$ until use.

\section{Ultramarathon}

The ultramarathon described elsewhere ${ }^{34}$ was held in Gifu Prefecture, Japan, on July 24 and 25, 2004. In brief, the race covered running and mountaineering $130 \mathrm{~km}$ over 2 days. On the first day, at $11 \mathrm{am}$, the participants started a full-length marathon to be completed within 6.5 hours. The next morning at $3.30 \mathrm{am}$, they resumed the race to run approximately $90 \mathrm{~km}$, including mountain climbing (about 1,100 $\mathrm{m}$ high) and then returning to the starting point within 15.5 hours. They were free to consume any food and beverage including alcohol.

\section{Measurements}

Red blood cells (RBCs), hematocrit (Ht), platelets, hemoglobin $(\mathrm{Hb})$, white blood cells (WBCs), and RBC indices, including mean corpuscular volume (MCV), mean corpuscular hemoglobin $(\mathrm{MCH})$, and mean corpuscular hemoglobin concentration (MCHC) were analyzed using XE2100 instrument (Sysmex, K.K., Kobe, Japan). Ferritin and insulin were assayed by chemical immunoluminescence, and $\mathrm{HbA}_{1} \mathrm{c}$, adrenaline (Ad), noradrenaline (NorAd), and dopamine by high performance liquid chromatography (HPLC). Cortisol and leptin were measured by radioimmunoassay (WALLAC1460SRL and AlokaAR-950 [Aloka, K.K., Tokyo, Japan]). Interleukin 6 (IL-6) (immunoassay 2nd generation) and tumor necrosis factor- $\alpha$ (TNF- $\alpha$ ) (chemiluminescent immunoassay) were analyzed by R\&D systems (Funakoshi, K.K., Tokyo, Japan). Adiponectin was measured by latex-enhanced immunoturbidimetric assay. C-reactive protein (CRP) (latex-enhanced immunonephelometrics) was measured using the Behring Nephelometer-II (Behring Company, Tokyo, Japan). Other serum parameters, including total protein (TP), albumin (Alb), indirect bilirubin (ID-Bil), direct bilirubin (D-Bil), total bilirubin (T-Bil), uric acid (UA), creatine kinase (CK), lactate dehydrogenase (LDH), aspartate aminotransferase (AST), alanine aminotransferase (ALT), gamma-glutamyl transferase (GGT), creatinine (Cr), blood urea nitrogen (BUN), free fatty acid (FFA), triglyceride (TG), high-density lipoprotein cholesterol (HDL-C), and total cholesterol (T-Chol) were determined using the Hitachi 7600 analyzer (Hitachi, K.K., Tokyo, Japan). Reference values are from the SRL Test Dictionary 2004. ${ }^{35}$

\section{Statistical analysis}

Study subjects' characteristics are shown as mean \pm standard deviation (SD). Each biomarker mean value is expressed with standard error (SE). Crude values were listed for blood cell counts (except for white blood cells), protein, $\mathrm{Hb}$, and RBC indices ( $\mathrm{MCV}, \mathrm{MCH}$, and $\mathrm{MCHC}$ ), whereas other serum indices were adjusted for the values of $\mathrm{Hb}$. Analysis of variance for repeated measures (repeated ANOVA), followed by Dunnett's post hoc multiple $t$-test, was applied to detect any difference from respective baseline values (SAS/ATAT Software: User's Guide, Version 9, 2008, SAS Institute Inc, Cary, NC, USA). Statistical significance was set at $P<0.05$ (two-tailed). SAS version 9 (SAS Institute Inc) was used for statistical analyses. ${ }^{36}$

\section{Results}

Twenty-one runners completed the race. However, because all the samples from three participants were not available, we studied blood biochemical markers of 18 runners aged $52.1 \pm 12.1$ years old (mean $\pm \mathrm{SD}$ ) (Table 1). Body mass index (BMI: $\mathrm{kg} / \mathrm{m}^{2}$ ) was $21.1 \pm 1.6$. They were all nonsmokers. 
Table I Subject characteristics $(n=18)$

\begin{tabular}{ll}
\hline Variables & Mean \pm standard deviation \\
\hline Age (years) & $52.1 \pm 12.1$ \\
Height $(\mathrm{cm})$ & $166.4 \pm 5.5$ \\
Weight $(\mathrm{kg})$ & $58.5 \pm 4.6$ \\
$\mathrm{BMl}\left(\mathrm{kg} / \mathrm{m}^{2}\right)$ & $21.1 \pm 1.6$ \\
$\mathrm{HbA}, \mathrm{c}(\%)$ & $5.0 \pm 0.3$ \\
\hline
\end{tabular}

Abbreviations: $B M I$, body mass index; $\mathrm{HbA}_{1} \mathrm{c}$, hemoglobin $\mathrm{A}_{1} \mathrm{c}$.

Average completion time for the 2-day ultramarathon was $18.3 \pm 0.7$ hours

The number of RBCs tended to increase during the race periods, significantly decreased below baseline after the race, and then started recovering to baseline from then onward (Table 2). Corpuscular components of $\mathrm{Ht}(\%)$ and Plt counts along with serum $\mathrm{Hb}$, TP, and Alb concentrations were more or less similar. RBC indices did not show any remarkable change and stayed within reference values throughout the observation time points.

Serum ID-Bil, and D-Bil and T-Bil levels adjusted for $\mathrm{Hb}$ concentrations, significantly elevated on Day 2 and Day 3 (peak), and then returned to baseline (Table 3). Ferritin elevated from Day 2, continued to increase from Day 3 (peak) to Day 5. UA significantly increased only on Day 1. CK began to rise from Day 1, rose sharply on Day 2 (peak) and Day 3, and then gradually returned to baseline levels. LDH started to elevate from Day 1, continued to increase from Day 2 (peak) to Day 7, and AST significantly rose from Day 2 up to Day 5, while ALT similarly increased on Day 2 and after the race. GGT remained almost unchanged at all points. Cr significantly increased from Day 1 to Day 3 but stayed within normal ranges, and BUN was elevated on Day 2 and Day 3.

FFA levels significantly enhanced during the race periods and stayed elevated after the race (Table 4). However, TG declined on Day 2 and Day 3, and began returning to baseline from then onward. HDL-C elevated on Day 2 and remained elevated up to Day 5. T-Chol concentrations decreased on Day 2 and Day 3, and returned to baseline afterward.

WBC counts and IL-6 levels sharply elevated during the race periods, and returned to baseline after the race (Table 5). CRP slowly increased on Day 2 and Day 3 and returned gradually to baseline. TNF- $\alpha$ did not show any significant change at all time points.

Ad, NorAd, and dopamine elevated during race periods and returned to baseline after the race (Table 6). Cortisol was elevated on Day 1 (not significant) and significantly on Day 2 and Day 5.

Insulin levels enhanced at baseline compared with reference values, but other day measurements remained lower than the lower limit of reference figures. Leptin concentrations decreased on Day 2 but essentially did not change after the race, staying within the reference value range. Adiponectin levels did not change during the race periods and increased on Day 5 and Day 7.

\section{Discussion}

As expected, RBC counts, Ht (\%), and Plt counts along with serum $\mathrm{Hb}, \mathrm{TP}$, and Alb concentrations significantly/ marginally elevated during the race periods, declined below baseline after the race, and then returned to baseline from then onward. The first elevation may be attributable to blood or hemoconcentrations via dehydration induced by high body temperature/perspiration from running and mountaineering under high temperature and humidity. ${ }^{1,13,15,26}$ The decrease and later recovery seem to be influenced by hemolysis owing not only to physical destruction of RBCs or so-called marching anemia but also to rehydration/hydration after the race.

For the other remaining biomarkers, adjustment was made with $\mathrm{Hb}$ values to diminish immediate effects not

Table 2 Changes in blood counts, hemoglobin and protein concentrations, and RBC indices

\begin{tabular}{|c|c|c|c|c|c|c|c|}
\hline & Reference values $^{\mathbf{a}}$ & Baseline $^{\mathrm{b}}$ & Day Ib & Day $2^{\text {b }}$ & Day 3 & Day $5^{b}$ & Day $7^{\mathrm{b}}$ \\
\hline $\operatorname{RBCs}\left(/ 10^{4} \mu \mathrm{L}\right)$ & $427-570$ & $446.9 \pm 9.4$ & $467.7 \pm 8.6$ & $460.2 \pm 7.6$ & $425.8 \pm 7.3^{c}$ & $419.8 \pm 7.2^{c}$ & $437.6 \pm 8.0$ \\
\hline $\mathrm{Ht}(\%)$ & $39.8-51.8$ & $42.34 \pm 0.66$ & $43.96 \pm 0.65$ & $43.22 \pm 0.55$ & $40.27 \pm 0.70$ & $39.73 \pm 0.38^{c}$ & $41.64 \pm 0.62$ \\
\hline Plt $\left(/ / 0^{4} \mu \mathrm{L}\right)$ & $13.1-36.2$ & $22.21 \pm 0.80$ & $24.93 \pm 1.67$ & $26.73 \pm 1.0 \mathrm{I}^{\mathrm{d}}$ & $20.7 I \pm 2.19$ & $20.95 \pm 1.15$ & $22.44 \pm 0.97$ \\
\hline $\mathrm{Hb}(\mathrm{g} / \mathrm{dL})$ & $13.5-17.6$ & $14.54 \pm 0.29$ & $15.13 \pm 0.30$ & $14.76 \pm 0.24$ & $13.69 \pm 0.28^{c}$ & $13.45 \pm 0.17^{c}$ & $14.12 \pm 0.26$ \\
\hline $\mathrm{TP}(\mathrm{g} / \mathrm{dL})$ & $6.7-8.3$ & $7.08 \pm 0.09$ & $7.59 \pm 0.11^{d}$ & $7.27 \pm 0.09$ & $6.63 \pm 0.08^{c}$ & $6.87 \pm 0.06$ & $7.04 \pm 0.08$ \\
\hline Alb (g/dL) & $3.9-4.9$ & $4.42 \pm 0.06$ & $4.81 \pm 0.07^{d}$ & $4.67 \pm 0.07^{d}$ & $4.28 \pm 0.06$ & $4.27 \pm 0.05$ & $4.30 \pm 0.06$ \\
\hline $\mathrm{MCV}(\mathrm{fL})$ & $82.7-101.6$ & $95.05 \pm 1.28$ & $94.26 \pm 1.28$ & $94.18 \pm 1.25$ & $94.75 \pm 1.47$ & $94.93 \pm 1.46$ & $95.37 \pm 1.29$ \\
\hline $\mathrm{MCH}(\mathrm{pg})$ & $28.0-34.6$ & $32.34 \pm 0.50$ & $32.39 \pm 0.50$ & $32.15 \pm 0.50$ & $32.2 I \pm 0.63$ & $32.15 \pm 0.58$ & $32.34 \pm 0.49$ \\
\hline MCHC (\%) & $31.6-36.6$ & $34.03 \pm 0.18$ & $34.38 \pm 0.20$ & $34.12 \pm 0.19$ & $33.97 \pm 0.21$ & $33.85 \pm 0.19$ & $33.92 \pm 0.18$ \\
\hline
\end{tabular}

Notes: ${ }^{a}$ Reference values are from the SRL Test Dictionary 2004. ${ }^{35}$ b Mean \pm standard error. ${ }^{\mathrm{c}}$ Decreased vs baseline $(P<0.05)$. ${ }^{\mathrm{d}}$ Increased vs baseline $(P<0.03)$.

Abbreviations: RBCs, red blood cells; Ht, hematocrit; Plt, platelet; Hb, hemoglobin; TP, total protein; Alb, albumin; MCV, mean corpuscular volume; MCH, mean corpuscular hemoglobin; MCHC, mean corpuscular hemoglobin concentration; SRL, Special Reference Laboratories. 
Table 3 Changes in various serum biochemical parameters with adjustment of hemoglobin concentrations

\begin{tabular}{|c|c|c|c|c|c|c|c|}
\hline & Reference values ${ }^{a}$ & Baseline $^{b}$ & Day I & Day $2^{\text {b }}$ & Day $3^{b}$ & Day $5^{b}$ & Day $7^{b}$ \\
\hline ID-Bil (mg/dL) & $0.1-0.8$ & $0.32 \pm 0.03$ & $0.48 \pm 0.04$ & $0.76 \pm 0.07^{c}$ & $1.01 \pm 0.10^{c}$ & $0.44 \pm 0.04$ & $0.23 \pm 0.04$ \\
\hline D-Bil (mg/dL) & $0.0-0.3$ & $0.20 \pm 0.01$ & $0.24 \pm 0.01$ & $0.36 \pm 0.03^{c}$ & $0.5 I \pm 0.03^{c}$ & $0.25 \pm 0.02$ & $0.20 \pm 0.02$ \\
\hline T-Bil (mg/dL) & $0.2-1.0$ & $0.5 I \pm 0.03$ & $0.72 \pm 0.05$ & $1.12 \pm 0.08^{c}$ & $1.51 \pm 0.12^{c}$ & $0.69 \pm 0.05$ & $0.43 \pm 0.05$ \\
\hline Ferritin $(\mu g / L)$ & $27-320$ & $47.04 \pm 7.72$ & $57.99 \pm 9.14$ & $65.11 \pm 9.88^{c}$ & $78.50 \pm \mathrm{I} .8 \mathrm{I}^{\mathrm{c}}$ & $73.24 \pm 10.11^{c}$ & $57.57 \pm 10.33$ \\
\hline $\mathrm{UA}(\mathrm{mg} / \mathrm{dL})$ & $3.7-7.0$ & $6.14 \pm 0.25$ & $7.57 \pm 0.75^{c}$ & $6.69 \pm 0.39$ & $6.72 \pm 0.36$ & $6.08 \pm 0.26$ & $6.31 \pm 0.26$ \\
\hline CK (IU/L) & $57-197$ & $214.2 \pm 46.0$ & $398.6 \pm 58.6$ & $3,716.3 \pm 493.3^{c}$ & $2,6|4.2 \pm 4| 0.4^{c}$ & $847.3 \pm 119.0$ & $360.4 \pm 88.0$ \\
\hline LDH (IU/L) & $115-245$ & $217.1 \pm 12.6$ & $286.2 \pm 14.0^{c}$ & $381.1 \pm 20.9^{c}$ & $334.7 \pm 20.1^{c}$ & $317.0 \pm 19.5^{c}$ & $280.3 \pm 17.6^{c}$ \\
\hline AST (IU/L) & $1-40$ & $24.5 \pm 2.56$ & $29.1 \pm 2.58$ & $91.8 \pm 11.78^{c}$ & $94.7 \pm 14.02^{c}$ & $55.6 \pm 6.45^{c}$ & $35.8 \pm 4.68$ \\
\hline ALT (IU/L) & $5-40$ & $21.5 \pm 1.97$ & $23.1 \pm 1.98$ & $36.2 \pm 3.12^{c}$ & $39.7 \pm 3.91^{c}$ & $43.2 \pm 4.39^{c}$ & $34.3 \pm 3.53^{c}$ \\
\hline GGT (IU/L) & $0-70$ & $42.8 \pm 6.50$ & $43.96 \pm 6.43$ & $49.04 \pm 8.19$ & $46.86 \pm 7.96$ & $51.16 \pm 7.75$ & $48.23 \pm 7.17$ \\
\hline $\mathrm{Cr}(\mathrm{mg} / \mathrm{dL})$ & $0.6 \mathrm{I}-1.04$ & $0.83 \pm 0.02$ & $1.08 \pm 0.06^{c}$ & $0.98 \pm 0.04^{c}$ & $0.98 \pm 0.04^{c}$ & $0.85 \pm 0.03$ & $0.86 \pm 0.03$ \\
\hline BUN (mg/dL) & $6-20$ & $|6.73 \pm| .0 \mid$ & $\mid 8.94 \pm 1.02$ & $23.38 \pm 1.17^{c}$ & $21.96 \pm 1.25^{c}$ & $16.58 \pm 0.94$ & $16.61 \pm 1.03$ \\
\hline
\end{tabular}

Notes: ${ }^{a}$ Reference values are from the SRL Test Dictionary 2004. ${ }^{35}$ bMean \pm standard error. Increased vs baseline $(P<0.05)$.

Abbreviations: ID-Bil, indirect bilirubin; D-Bil, direct bilirubin; T-Bil, total bilirubin; CK, creatine kinase; LDH, lactate dehydrogenase; UA, uric acid; AST, aspartate aminotransferase; ALT, alanine aminotransferase; GGT, gamma-glutamyl transferase; Cr, creatinine; BUN, blood urea nitrogen; SRL, Special Reference Laboratories.

only of dehydration or hemoconcentrations but also of rehydration/hydration. ${ }^{1,13,15,26}$ The changes in serum ID-Bil (nonconjugated bilirubin), in particular, together with D-Bil (conjugated bilirubin) and T-Bil may be, in part, attributed to hemolysis/physical destruction of RBCs or waste products of $\mathrm{Hb} \cdot{ }^{15,20,23}$ Ferritin was quickly deployed from the liver iron storage in response to hemolytic anemia and remained high after the race through the homeostasis system or self-defense response. . $^{1,28}$

Serum UA, CK, and LDH similarly increased according to production of energy and muscle damage during the race. ${ }^{1,13-15,17-26,28}$ UA is a final waste product of protein, amino acids, and DNA and is particularly increased on Day 1, during which nonprofessional, middle-aged runners had to complete the uphill full marathon within 6.5 hours with aerobic running along with an anaerobic (high-intensity) struggle during midday, with high temperature and humidity. CK, as is well known, is a catalyzing enzyme of creatine phosphorylation in the phosphagen energy system. LDH is a rate-limiting enzyme to adjust reactions from pyruvate to lactic acid in the glycolysis system of the terminal TCA cycle. Both CK and LDH are escape markers of muscle damage. Both enzymes elevated quickly on Day 1, boosted on Day 2, and remained elevated after the race. CK elevated at baseline, showing that participants have had training before the race.

AST and ALT are aminotranferases. AST is localized in the skeletal muscles, RBCs, heart, and liver, and ALT is leaked from damaged hepatocytes and skeletal muscles. ${ }^{1,13,17-19,21,23-26,28}$ Both AST and ALT increased on Day 2 and prolonged after the race, but ALT stayed within normal range. GGT is specifically located in the liver and responds to consumption of alcohol and certain drugs, fatty liver, and biliary tract diseases; GGT remained almost unchanged at all time points. Thus, liver damage, if any, caused by the running and mountaineering was not so severe.

Serum $\mathrm{Cr}$ is a terminal product of irreversible cyclization reaction of nonenzymatic dephosphorylation of creatine phosphate, and it is used as an indicator of renal function or GFR (glomerular filtration rate). BUN is a terminal breakdown product of protein or muscles. ${ }^{1,14,15,20,28}$ Thus, these markers or protein waste products may be naturally elevated due to muscle injuries by running and mountaineering. Increase of Cr suggests that GFR has temporarily been damaged due to an overdose of muscle damage and protein wastes, but the elevation patterns (even if statistically significant) were not very remarkable and remained almost within the normal

Table 4 Changes in serum lipid parameters with adjustment of hemoglobin concentrations

\begin{tabular}{llllllll}
\hline & Reference values $^{\mathbf{a}}$ & Baseline $^{\mathrm{b}}$ & Day I $^{\mathrm{b}}$ & Day 2 $^{\mathrm{b}}$ & Day 3 $^{\mathrm{b}}$ & Day 5 $^{\mathrm{b}}$ & Day 7 $^{\mathrm{b}}$ \\
\hline FFA (mEq/dL) & $0.14-0.85$ & $0.12 \pm 0.02$ & $1.15 \pm 0 . \mathrm{I}^{\mathrm{c}}$ & $1.85 \pm 0.16^{\mathrm{c}}$ & $1.04 \pm 0.05^{\mathrm{c}}$ & $0.58 \pm 0.12^{\mathrm{c}}$ & $0.42 \pm 0.06$ \\
TG (mg/dL) & $50-149$ & $118.3 \pm 19.5$ & $101.50 \pm 15.0$ & $45.86 \pm 5.6^{\mathrm{d}}$ & $39.53 \pm 4.7^{\mathrm{d}}$ & $76.7 \pm 6.9$ & $144.1 \pm 38.9$ \\
HDL-C (mg/dL) & $40-86$ & $81.00 \pm 4.3$ & $85.83 \pm 5.0$ & $88.18 \pm 5.4^{\mathrm{c}}$ & $92.44 \pm 5.3^{\mathrm{c}}$ & $89.46 \pm 4.8^{\mathrm{c}}$ & $81.28 \pm 5.0$ \\
T-Chol (mg/dL) & $150-219$ & $210.6 \pm 6.4$ & $219.50 \pm 6.88$ & $197.20 \pm 7.60^{d}$ & $196.88 \pm 7.01^{d}$ & $202.88 \pm 6.71$ & $196.67 \pm 8.20^{d}$ \\
\hline
\end{tabular}

Notes: ${ }^{a}$ Reference values are from the SRL Test Dictionary 2004.35 bMean \pm standard error. 'Increased vs baseline $(P<0.03)$. ${ }^{\mathrm{d}}$ Decreased vs baseline $(P<0.05)$.

Abbreviations: FFA, free fatty acid; TG, triglyceride; HDL-C, high-density lipoprotein cholesterol; T-Chol, total cholesterol; SRL, Special Reference Laboratories. 
Table 5 Changes in serum inflammation parameters with adjustment of hemoglobin concentrations

\begin{tabular}{llllllll}
\hline & Reference values $^{\mathbf{a}}$ & Baseline $^{\mathbf{b}}$ & Day I $^{\mathbf{b}}$ & Day 2 $^{\mathbf{b}}$ & Day 3 $^{\mathbf{b}}$ & Day 5 $^{\mathbf{b}}$ & Day $^{\mathbf{7}^{\mathbf{b}}}$ \\
\hline WBC $(/ \mu \mathrm{L})$ & $3,900-9,800$ & $4,849.4 \pm 235.0$ & $10,575.8 \pm 669.3^{\mathrm{c}}$ & $1 \mathrm{I}, 823.3 \pm 817.2^{\mathrm{c}}$ & $5,969.8 \pm 422.1$ & $5,938.6 \pm 550.7$ & $5,225.1 \pm 350.4$ \\
IL-6 $(\mathrm{pg} / \mathrm{mL})$ & $0-4.0$ & $0.77 \pm 0.26$ & $26.52 \pm 5.05^{\mathrm{c}}$ & $19.28 \pm 1.99^{\mathrm{c}}$ & $3.35 \pm 0.96$ & $6.53 \pm 4.16$ & $1.40 \pm 0.38$ \\
CRP $(\mathrm{mg} / \mathrm{dL})$ & $0-0.30$ & $0.07 \pm 0.03$ & $0.07 \pm 0.03$ & $0.72 \pm 0.14^{\mathrm{c}}$ & $1.45 \pm 0.29^{\mathrm{c}}$ & $0.64 \pm 0.18$ & $0.57 \pm 0.28$ \\
TNF- $\alpha(\mathrm{pg} / \mathrm{mL})$ & $0-5$ & $0.91 \pm 0.06$ & $0.95 \pm 0.09$ & $0.84 \pm 0.06$ & $0.95 \pm 0.08$ & $0.98 \pm 0.07$ & $1.15 \pm 0.17$ \\
\hline
\end{tabular}

Notes: ${ }^{a}$ Reference values are from the SRL Test Dictionary 2004. ${ }^{35}$ bMean \pm standard error. Increased vs baseline $(P<0.05)$.

Abbreviations: WBCs, white blood cells; IL-6, interleukin-6; CRP, C-reactive protein; TNF- $\alpha$, tumor necrosis factor- $\alpha$; SRL, Special Reference Laboratories.

range, because runners' renal filtration function was kept normal during and after the long endurance race.

Because energy was produced by $\beta$-oxidation of FFAs during aerobic physical exercise, FFAs rose during the race periods. TG was decreased during the race period and after the race, because TG was mobilized from visceral and subcutaneous adipose tissues along with TG in the VLDL-C (very low-density lipoprotein cholesterol) and broken down to FFAs by lipase. ${ }^{1,12,13,16,19,23,28}$ In other words, TG concentrations may be compensated by FFA levels. As is well known, HDL-C is increased by habitual physical exercise and sports, which was the case in this study: that is, participants' baseline HDL-C values were located in the upper range of reference values. HDL-C increased from Day 2 to Day 5 , which is possibly due to the fact that VLDL-C is converted to HDL-C by lipoprotein lipase. Because TG levels are strongly influenced by consumption of food and beverages, non-HDL-C (for LDL-C, estimated by subtracting HDL-C from T-Chol instead of using Friedewald formula when food and beverages are freely consumed) was significantly decreased from Day 2 to Day 5 (data not shown).

In response to ROS, ${ }^{7-11}$ inflammation, or muscle injuries, leukocyte migration (leukocyte-plania or chemotaxis) quickly occurs from the marginal pool (the capillary vessels) to the circulating pool and IL-6 is released from T-cells and macrophages to control humoral immune response. ${ }^{1,14,15,20-22,25-28}$ WBC counts and IL-6 levels enhanced only during the race periods (sharply on Day 1 and on Day 2) and returned to baseline after the race. IL-6 subsequently activates the induction of CRP (an acute-phase protein) from the liver. CRP increased on Day 2 and Day 3, and then returned to baseline. Thus, WBCs and IL-6 were selected as immediate inflammation markers, whereas CRP was categorized as a secondary biomarker; but CRP should not be overlooked, because the changes were remarkable (up to 10-fold elevation from baseline). TNF- $\alpha$, a cytokine secreted from adipocytes related various acute and chronic inflammation showed no significant temporal differences. The increase on Day 7 (although not significant) may suggest that TNF- $\alpha$ may be a long-term inflammation parameter related to the onset of lifestyle-related diseases, including metabolic syndrome, diabetes mellitus, and cancer. ${ }^{2,3,21,22}$

Catecholamines (Ad [epinephrine], NorAd [norepinephrine], and dopamine) were elevated during the race periods and recovered to baseline after the race. Dopamine is a precursor of Ad and NorAd. Ad and NorAd are liberated from the medulla of the adrenal gland. ${ }^{1,5,6} \mathrm{Ad}$, NorAd, and dopamine may have plausibly been enhanced by sympathetic dominance due to intense physical exercise and mental stress. Cortisol (glucocorticoid) is secreted from the cortex of the adrenal gland. The significant increment in cortisol on Day 2 (just after the long endurance running) seems to be compatible with the fact that cortisol compensates the blood glucose level. However, an elevation at baseline appeared paradoxical, because runners freely consumed any food and beverages, and blood glucose concentrations were presumably high. The

Table 6 Changes in serum hormones with adjustment of hemoglobin concentrations

\begin{tabular}{|c|c|c|c|c|c|c|c|}
\hline & Reference values $^{a}$ & Baseline $^{b}$ & Day Ib & Day $2^{\text {b }}$ & Day 3 ${ }^{b}$ & Day $5^{b}$ & Day $7^{\mathrm{b}}$ \\
\hline Ad (pg/mL) & $0-100$ & $15.78 \pm 1.30$ & $42.99 \pm 9.69^{d}$ & $50.92 \pm 13.95^{d}$ & $8.55 \pm 2.46$ & $10.98 \pm 1.75$ & $14.22 \pm 2.63$ \\
\hline NorAd (pg/mL) & $100-450$ & $78.50 \pm 9.24$ & $539.19 \pm 115.92^{\mathrm{d}}$ & $533.16 \pm 141.33^{d}$ & $36.67 \pm 3.63$ & $7 I .31 \pm 14.44$ & || $6.76 \pm 20.5 \mid$ \\
\hline Dopamine (pg/dL) & $0-20$ & $12.22 \pm 3.23$ & $209.78 \pm 102.12^{\mathrm{d}}$ & $90.13 \pm 36.79$ & $7.46 \pm 1.04$ & $7.00 \pm 0.66$ & $8.00 \pm 0.80$ \\
\hline Cortisol ( $\mu \mathrm{g} / \mathrm{dL})$ & $7.1-15$ & $16.62 \pm 0.95$ & $20.12 \pm 2.18$ & $24.57 \pm 2.25^{d}$ & $16.92 \pm 1.45$ & $22.27 \pm 1.18^{d}$ & $21.19 \pm 0.89$ \\
\hline Insulin $(\mu \mathrm{U} / \mathrm{mL})^{c}$ & $5.0-15$ & $22.12 \pm 3.05$ & $2.69 \pm 0.74^{\mathrm{e}}$ & $2.58 \pm 0.43^{e}$ & $3.06 \pm 0.50^{\mathrm{e}}$ & $3.46 \pm 0.37^{\mathrm{e}}$ & $4.29 \pm 0.55^{\mathrm{e}}$ \\
\hline Leptin (ng/mL) & $0.9-13$ & $2.44 \pm 0.13$ & $2.53 \pm 0.19$ & $1.86 \pm 0.10^{\mathrm{e}}$ & $2.35 \pm 0.13$ & $2.74 \pm 0.14$ & $2.75 \pm 0.15$ \\
\hline Adiponectin $(\mu g / m L)$ & $>4.0$ & $10.89 \pm 1.18$ & $11.63 \pm 1.39$ & $11.91 \pm 1.58$ & $11.25 \pm 1.37$ & $12.48 \pm 1.45^{d}$ & $12.54 \pm 1.39^{d}$ \\
\hline
\end{tabular}

Notes: aReference values are from the SRL Test Dictionary 2004. ${ }^{35}$ bMean \pm standard error. Insulin levels elevated at baseline, and other day measurements stayed within the reference value range. Increased vs baseline $(P<0.05)$. ${ }^{e} D e c r e a s e d$ vs baseline $(P<0.05)$.

Abbreviations: Ad, adrenaline; NorAd, noradrenaline; SRL, Special Reference Laboratories. 
precise reason for the elevation on Day 2 and Day 5 is also unknown to us and should be examined along with the blood glucose concentrations and insulin level along with markers of immune response in the experimental setting. In terms of mental stress or general adaptation syndrome, further studies are needed on dopamine and cortisol in the role of neurotransmitters of the central nervous system, so as to conduct ad hoc multiphasic analyses of mental stress parameters, including serotonin, kynurenine, $\beta$-endorphin, and chromogranin together with mental stress questionnaires.

Insulin levels were elevated at baseline for homeostasis of blood glucose, but other Day measurements stayed within the reference figure range. All runners arbitrarily consumed food and beverages for the endurance race, and insulin was secreted against enhanced blood glucose. The insulin level did not change on Day 1 and Day 2, although runners also ad lib consumed food and beverages during the race periods, which may be due to the fact that elevated blood glucose was neutralized by high energy consumption of endurance running. Previous studies showed decreased leptin levels after very strenuous exercises like full marathon, or $100 \mathrm{~km}$ run, reflecting high minus energy balance. ${ }^{29,30}$ In the present study, no reduction in leptin levels was noted on Day 1, suggesting that there was no energy minus balance because they freely consumed foods and beverages before and during the full marathon; but there appeared to be energy minus balance on Day 2 because they had longer $90 \mathrm{~km}$ running. Previous studies observed increased adiponectin concentrations only after higher density exercises with severe energy deprivation. ${ }^{31-33}$ Elevations of adiponectin levels on Day 5 and Day 7 in this study may be considered as beneficial effects of physical exercise, including enhancement of insulin sensitivity and activation of oxidation of fatty acids. ${ }^{37}$ Markers related to the metabolism of carbohydrates/glucose and insulin, in particular, should be studied in depth using a metabolic room.

As is expected, postrace patterns of ferritin, CK, LDH, AST, FFAs, WBCs, and IL-6 elevation or of TG decline were also observed in some earlier studies. . $^{18,21,25,27,28}$

Moreover, the change in biomarker values (ratio to the baseline [maximum value/baseline] rather than their difference [maximum value - baseline]) were generally well correlated not only with the intensity or gross speed (distance/ hour) but also with the amount (distance and time limit). Although the changes in $\mathrm{CK}, \mathrm{LDH}$, and AST levels if participants in this race were estimated on the basis of a small number of heterogeneous individuals, the changes seemed roughly smaller than those observed in the other races with equivalent running distance, ${ }^{14,18,21,25}$ which appeared, in part, due to the following facts: the race was "maranic" (derived from the words marathon and picnic) and not competitive; the time limit was not strict, most runners were amateurs; and they took a one-night rest.

For precise and detailed comparisons, however, we should take into account the characteristics of runners (age, sex, amount of training, fitness level, and ethnicity), setting of the race (distance and time limit), biomarker analysis methods, reference values, and environmental factors, including temperature and humidity, and we should prepare a sophisticated study protocol to match/adjust parameters for in-depth comparisons. Relative validity studies on the present biomarkers are needed against more valid biomarkers, including markers of inflammation, ROS, and DNA damage ${ }^{5-11,22,25,28}$ along with a questionnaire on mental stress and fatigue. ${ }^{1,6}$ Future studies are warranted to verify the present biomarkers as potential indices for assessing the intensity and amount of long-distance running.

There are some limitations in the present study. Because this study was conducted on runners actually involved in an endurance race, not a metabolic laboratory setting, the sample size setting or power calculation was, a priori, not available. In fact, the sample size was not large enough to perform individual investigation, or subclass analyses, including subtype/isozyme analyses, including $\mathrm{CK}$ and $\mathrm{LDH}$, comparisons between high (quick) vs low (slow) responders, or studies by genetic polymorphism. As the participants arbitrarily consumed food and beverages, markers of carbohydrate/glucose metabolism (insulin in particular) should be deliberately evaluated. In addition, studies of ROS indices, DNA damage indices, immunological parameters, including humoral and cellular immune response indices, together with mental stress markers were not systematically performed, and detailed discussion was not available for those indices.

In conclusion, in this study changes in blood biochemical markers of long-distance runners were measured and categorized into three patterns. Among them, ID-Bil, ferritin, CK, LDH, AST, FFAs, WBCs, IL-6, and Ad/NorAd/dopamine or TG were selected as biomarkers demonstrating typical temporal changes, appearing useful for nonprofessional athletes to recognize optimal physical activity levels, duration, and total energy expenditure for enhancing physical fitness and monitoring physical/mental conditioning as well as for prevention of overtraining and physical damage. The observations could also be effectively and efficiently applied by persons in ordinary life for promoting health and preventing noncommunicable diseases, upgrading activities of daily life, elongating life/ healthy life expectancy, and enhancing quality of life. 


\section{Acknowledgments}

This study was supported in part by a Grant-in-Aid from the Ministry of Education, Culture, Sports, Science, and Technology, Japan (15390208 [from 2003 to 2005]). We appreciate the generous participation of the runners in our study along with the chairman and organizing committee of the Maranic race. We also thank Ms T Fujii, Ms Y Kubo, Ms N Nakanishi, Ms Y Ito, Ms K Higuchi, and Ms M Watanabe for their technical assistance.

\section{Disclosure}

The authors report no conflicts of interest in this work.

\section{References}

1. Nakano S. Illustration: The Merits and Demerits of Physical Exercise on Human Body. 2nd ed. Tokyo, Japan: Ishiyaku; 1997. Japanese.

2. Hamer M, Chida Y. Walking and primary prevention: a meta-analysis of prospective studies. Br J Sports Med. 2008;42:238-245.

3. De Fronzo RA, Ferrannini E. Insulin resistance. A multifaceted syndrome responsible for NIDDM, obesity, hypertension, dyslipidemia, and atherosclerotic cardiovascular disease. Diabetes Care. 1991;14:173-194.

4. World Cancer Research Fund/American Institute for Cancer Research. Food, Nutrition, Physical Activity, and the Prevention of Cancer: A Global Perspective. Washington, DC: American Institute for Cancer Research; 2007.

5. Pedersen BK, Hoffman-Goetz L. Exercise and the immune system: regulation, integration, and adaptation. Physiol Rev. 2000;80:1055-1081.

6. Agawa H, Yamada N, Enomoto Y, et al. Changes of mental stress biomarkers in ultramarathon. Int J Sports Med. 2008;29:867-871.

7. Leaf DA, Kleinman MT, Hamilton M, Detrick RW. The exercise-induced oxidative stress paradox: the effects of physical exercise training. Am J Med Sci. 1999;317:295-300.

8. Niess AM, Dickhuth HH, Northff H, Fehrenbach E. Free radicals and oxidative stress in exercise - immunological aspects. Exerc Immunol Rev. 1999;5:22-56.

9. Miyata M, Kasai H, Kawai K, et al. Changes of urinary 8-hydroxydeoxyguanosine levels during a two-day ultramarathon race period in Japanese non-professional runners. Int J Sports Med. 2008;29:27-33.

10. Hattori N, Hayashi T, Nakachi K, et al. Change of ROS during a two-day ultra-marathon race. Int J Sports Med. 2009;30:426-429.

11. Marumoto M, Suzuki S, Arakawa K, et al. Changes in thioredoxin concentrations: an observation an ultra-marathon race. Environ Health Prev Med. 2010;15:129-134.

12. Kuusi T, Kostiainen E, Vartianinen E, et al. Acute effects of marathon running on levels of serum lipoproteins and androgenic hormones in healthy males. Metabolism. 1984;33:527-531.

13. van Rensburg JP, Kielblock AJ, van der Linde A. Physiologic and biochemical changes during a triathlon competition. Int J Sports Med. 1986;7:30-35.

14. Rama R, Ibanez J, Riera M, Prats MT, Pages T, Palacios L. Hematological, electrolyte, and biochemical alterations after a $100-\mathrm{km}$ run. Can J Appl Physiol. 1994;19:411-420.

15. Kratz A, Lewandrowski KB, Siegel AJ, et al. Effect of marathon running on hematologic and biochemical laboratory parameters, including cardiac markers. Am J Clin Pathol. 2002;118:856-863.

16. Jensen MD. Fate of fatty acids at rest and during exercise: regulatory mechanisms. Acta Physiol Scand. 2003;178:358-390.
17. Smith JE, Garbutt G, Lopes P, Pedoe DT. Effects of prolonged strenuous exercise (marathon running) on biochemical and haematological markers used in the investigation of patients in the emergency department. Br J Sports Med. 2004;38:292-294.

18. Wu HJ, Chen KT, Shee BW, Chang HC, Huang YJ, Yang RS. Effects of $24 \mathrm{~h}$ ultra-marathon on biochemical and hematological parameters. World J Gastroenterol. 2004;10:2711-2714.

19. Kobayashi Y, Takeuchi T, Hosoi T, Yoshizaki H, Loeppky JA. Effect of a marathon run on serum lipoproteins, creatine kinase, and lactate dehydrogenase in recreational runners. Res $Q$ Exerc Sport. 2005;76:450-455.

20. Suzuki K, Peake J, Nosaka K, et al. Changes in markers of muscle damage, inflammation and HSP70 after Ironman Triathlon race. Eur J Appl Physiol. 2006;98:525-534.

21. Kim HJ, Lee YH, Kim CK. Biomarkers of muscle and cartilage damage and inflammation during a $200 \mathrm{~km}$ run. Eur J Appl Physiol. 2007;99:443-447.

22. Neubauer O, Konig D, Wagner KH. Recovery after an Ironman Triathlon: sustained inflammatory responses and muscular stress. Eur J Appl Physiol. 2008;104:417-426.

23. Lippi G, Schena F, Montagnana M, Salvagno GL, Banfi G, Guidi GC. Significant variation of traditional markers of liver injury after a halfmarathon run. Eur J Intern Med. 2011;22:e36-e38.

24. Lippi G, Schena F, Salvagno GL, Aloe R, Banfi G, Guidi GC. Footstrike haemolysis after a 60-km ultramarathon. Blood Transfus. 2012;10:377-383.

25. Waśkiewicz Z, Kłapcińska B, Sadowska-Krępa E, et al. Acute metabolic responses to a 24-h ultra-marathon race in male amateur runners. Eur J Appl Physiol. 2012;112:1679-1688.

26. Del Coso J, Fernández D, Abián-Vicen J, et al. Running pace decrease during a marathon is positively related to blood markers of muscle damage. PLoS One. 2013;8:e57602.

27. Traiperm N, Gatterer H, Burtscher M. Plasma electrolyte and hematological changes after marathon running in adolescents. Med Sci Sports Exerc. 2013;45:1182-1187.

28. Kłapcińska B, Waśkiewicz Z, Chrapusta SJ, Sadowska-Krępa E, Czuba M, Langfort J. Metabolic responses to a 48-h ultra-marathon run in middle-aged male amateur runners. Eur J Appl Physiol. 2013;113:2781-2793.

29. Zaccaria M, Ermolao A, Roi GS, Englaro P, Tegon G, Varnier M. Leptin reduction after endurance races differing in duration and energy expenditure. Eur J Appl Physiol. 2002;87:108-111.

30. Leal-Cerro A, Garcia-Luna PP, Astorga R, et al. Serum leptin levels in male marathon athletes before and after the marathon run. J Clin Endocrinol Metab. 1998;83:2376-2379.

31. Rabe K, Lehrke M, Parhofer KG, Broedl UC. Adipokines and insulin resistance. Mol Med. 2008;14:741-751.

32. Modan-Moses D, Stein D, Pariente C, et al. Modulation of adiponectin and leptin during refeeding of female anorexia nervosa patients. J Clin Endocrinol Metab. 2007;92:1843-1847.

33. Roupas ND, Mamali I, Maragkos S, et al. The effect of prolonged aerobic exercise on serum adipokine levels during an ultra-marathon endurance race. Hormones. 2013;12(2):275-282.

34. Tokudome S, Kuriki K, Yamada N, et al. Anthropometric, lifestyle and biomarker assessment of Japanese non-professional ultra-marathon runners. J Epidemiol. 2004;14:161-167.

35. Special Reference Laboratory. Special Reference Laboratory, Test Dictionary. Tokyo, Japan: Special Reference Laboratory; 2004

36. SAS Institute. SAS/STAT Software: User's Guide, Version 9.2. Cary, NC: SAS Institute Inc; 2008.

37. Bouassida A, Chamari K, Zaouali M, Feki Y, Zbidi A, Tabka Z. Review on leptin and adiponectin responses and adaptations to acute and chronic exercise. Br J Sport Med. 2010;44:620-630. 


\section{Publish your work in this journal}

Open Access Journal of Sports Medicine is an international, Visit http://www.dovepress.com/testimonials.php to read real quotes peer-reviewed, open access journal publishing original research, from published authors.

reports, reviews and commentaries on all areas of sports

medicine. The manuscript management system is completely

online and includes a very quick and fair peer-review system.

Submit your manuscript here: http://www.dovepress.com/open-access-journal-of-sports-medicine-journal 